\title{
High prevalence of smoking in Northern Greece
}

\author{
Lazaros T. Sichletidis*, Diamantis Chloros, loannis Tsiotsios, \\ loannis Kottakis, Ourania Kaiafa, Stella Kaouri, \\ Alexandros Karamanlidis, Dimitrios Kalkanis, Sotirios Posporelis
}

\author{
Pulmonary Clinic, Aristotle University of Thessalonica, and the Laboratory for the Investigation of \\ Environmental Diseases, G. Papanicolaou General Hospital, Exochi, Thessalonica, 57010 Greece
}

Received 23 April 2005; accepted 11 January 2006

\begin{abstract}
KEYWORDS
Smoking;

Adolescent smoking;

Teachers;

Medical doctors;

Epidemiology

copyright

Summary

Aim: To investigate the prevalence of smoking in the sene Dodnctution and in specific population sub-groups in Northern Greect. $S$

Methods: A cross-sectional study ras en dultea during the period 1999-2001 on a $5 \%$ sample $(23,8,10)$ Cthdse people aged belween 21 to 80 out of a total

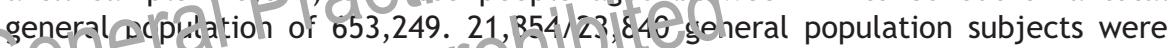
i) students, 50.7 medical doctors within the National Health System, 825 teachers, and 624 sulbjec s 1 ho regularly exercised in a privately-owned gym. A specially modified IERF study group questionnaire was used.

Results: $34.4 \%$ of the general population sample were current smokers $(47.8 \%$ of males and $21.6 \%$ of females). Smoking prevalence rates in the population sub-groups were: $29.6 \%$ of high school students; $40.7 \%$ of medical students; $44.9 \%$ of medical doctors; $46.4 \%$ of teachers; and $36.9 \%$ of the gym group.

Conclusion: The prevalence of smoking in Northern Greece is high. High school and medical students present with high smoking rates, and the same situation is observed in medical doctors and teachers. An intensification of preventive antismoking measures is required.

(c) 2006 General Practice Airways Group. Published by Elsevier Ltd. All rights reserved.
\end{abstract}

\section{Introduction}

The recognition that tobacco smoking represents a significant health hazard has led to the implementation of smoking restriction programs in many countries.

\footnotetext{
* Corresponding author. Tel.: +30 2310992363.

E-mail address: dchloros@msn.com (L.T. Sichletidis).
}

In Greece, following a twenty-one year period of relative inactivity, the Ministry of Health and Welfare has recently re-implemented an antismoking campaign. One of the reasons for this is data from 1990 showing that Greece has the highest annual incidence of lung neoplasm in young men under the age of 45 amongst all European Union countries - 4.1 per 100,000 population as opposed to an EU average of 2.5 per 100,000 [1]. This 
high incidence corresponds to the increased annual per capita consumption of cigarettes observed in Greece over the last 20 years; Greece was ranked 16th worldwide with an annual per capita consumption of 2,640 cigarettes in 1970-72, fourth worldwide (3,440 cigarettes) in 1980-82, and second worldwide (3,590 cigarettes) in 1990-92, according to World Health Organisation (WHO) data [2].

In Greece, smoking data are based on statistical surveys of cigarette sales from the Ministry of Commerce, and not on direct epidemiological investigations. This study attempts to fill this gap, by examining the prevalence of smoking in the general population and in special population groups. These groups were: (a) High school students, since they properly best reflect the evolution of the habit of smoking and near future trends; (b) Medical students of the Aristotle University of Thessalonica, since they will be the future health experts; (c) Medical doctors of the National Health System, since they are the most powerful opinion group with regard to health issues; (d) Teachers, since their influence on both students and the general population is considered to be important; and (e) Exercising persons, since they reflect, in practice, the concept of a healthier lifestyle.

The aim of this study was to invertigdte the prevalence of smoking in the gereral population and in specific ppollation sub-groups in Northern Greece. The Exact knowledge o: toenten or the smoking epidemic is not only of scientific interest but is of practical importance. Increased awareness of the problem will facilitate action plans, including mass media-based anti-smoking campaigns, and State-driven anti-smoking initiatives in workplaces, schools and universities.

\section{Methods}

The study was conducted in ten cities in Northern Greece on a total population of 653,249 people. The cities studied were: Thessalonica and Kavala (the two largest cities in Northern Greece, with important commercial harbors and a population of 369,987 and 63,774 respectively); Kozani $(35,242$ people) and Ptolemaida ( 28,679 people), two cites within an industrially developed area; Grevena (in a mountainous region with a population of $37,017)$; Florina $(17,069$ people), Kastoria $(20,590$ people) and Edessa (25,307 people), three semimountainous cities; and finally, Kilkis $(25,134$ people) and Yiannitsa (30,450 people), two cities in a large plain area. Thessalonica is sheer urban and the second biggest city in Greece, whereas Kavala is a regional urban city. Florina, Kilkis and Grevena are three of the poorest cities in Greece. The first two are agricultural cities while the basic occupation of Grevena is stockbreeding. Ptolemaida and Kozani are important industrial areas where $75 \%$ of the country's electricity is produced. Edessa and Yiannitsa are two quite rich cities with a mixed economy. Finally, Kastoria used to be the main fur-production city worldwide with the greatest income per person.

Subjects were selected from the consumer records of the Water Supply Organization based on systematic random sampling. The above method was used due to the large sample of the study. In addition, university students made door-to-door visits and filled in the questionnaires. A total of 21,854 questionnaires were completed with the help of researchers, from a total of 23,840 subjects initially selected to undergo examination i.e., $5 \%$ of the total population between 21 and 80 years old. The questionnaire was given to the interviewed subjects and consequently collected. Permission was granted from the relevant competent authorities.

Certain special popilation virt-groups were also investigated ising ifie same method (immediate 'ind (ônand collection):

(A) Mich Cchod students $(9,276)$ from six cities (IIhessalonica, Kozani, Florina, Ptolemaida, Grevena and Kastoria), aged $17.5 \pm 1.3$ years,

(B) Medical students of the Aristotle University of Thessalonica $(1,072)$ aged $22.4 \pm 2.4$ years,

(C) Medical doctors of the National Health System (597) from Hospitals in six cities, aged $36.9 \pm 8.2$ years,

(D) Teachers (825) from six cities, aged $39.8 \pm 7.1$ years

(E) Exercising persons (624) from a privatelyowned gym in Thessalonica, aged 29.2 \pm 9.6 years.

The research was conducted in the period between 1999-2001 and a special modified ICRF study group questionnaire was used [3] (see Appendix A). Questionnaires were anonymous, so confidentiality was ensured.

A smoker was considered a person who was smoking at least one cigarette daily, whereas an exsmoker was a person who had been smoking at least one cigarette on a daily basis for at least one year and had quit smoking over the previous 12 months. All other subjects were regarded as non-smokers and handed in uncompleted questionnaires.

For the statistical analysis, the test $x^{2}$ was used. 
Table 1 Smoking habits in the general population of Northern Greece: smoking prevalence according to age groups, and the smoking history in terms of pack-years, for male and female subjects

\begin{tabular}{|c|c|c|c|c|c|}
\hline \multirow[t]{2}{*}{ Age } & \multicolumn{2}{|c|}{ Smokers } & \multicolumn{2}{|c|}{ Ex smokers } & \multirow{2}{*}{$\begin{array}{l}\text { Non smokers } \\
\%\end{array}$} \\
\hline & $\%$ & Pack-years & $\%$ & Pack-years & \\
\hline \multicolumn{6}{|l|}{ (a) Men } \\
\hline $21-40$ & 59.5 & $17.7 \pm 16.2$ & 13.6 & $14.9 \pm 8.8$ & 26.9 \\
\hline $41-60$ & 47.7 & $41 \pm 22.6$ & 27.8 & $36.8 \pm 26$ & 24.5 \\
\hline $61-80$ & 27.2 & $55.5 \pm 30.5$ & 32.9 & $47.9 \pm 27.3$ & 39.9 \\
\hline \multicolumn{6}{|c|}{ (b) Women } \\
\hline $21-40$ & 40.2 & $8.5 \pm 8.4$ & 2.6 & $10.8 \pm 6.6$ & 57.2 \\
\hline $41-60$ & 15 & $18.3 \pm 18$ & 2.6 & $20.5 \pm 14.5$ & 82.4 \\
\hline $61-80$ & 2.4 & $23.3 \pm 16$ & 1.7 & $27.6 \pm 22.3$ & 95.9 \\
\hline
\end{tabular}

\section{Results}

Smoking prevalence figures in the general population sample are presented in Table 1. Subjects are classified as current smokers, exsmokers and non (ever)-smokers, and the Table shows the smoking prevalence by age group, and the smoking history according to pack-years (the number of daily smoked cigarettes, multiplied by the years of smoking, divided by 20), for male and female subjects separately.

Overall, the percentage of current smokers decreases as a function of increasing age, whereas the number of pack-years (i.e sumu!a'ity/2 Exposure to tobacco smoke) is an pricxinat: (ly double for men compared to v'ounel. The number of ex : nlokers increases vich age in men, b it ces eases nin women, due to the relatively recent spread of smoking among women in Greece. In line with this, in females there is a considerably higher percentage of non-smokers (i.e. never smoked) in the older age groups.

In order to define the overall smoking rates in the general population, demographic data for the year $\mathbf{2 0 0 0}$ from the National Statistical Service of Greece have been considered. Accordingly, the overall Greek population is 10.6 million, grouped by age as follows: $21-40$ years ( $14.8 \%$ of the total male population- $14.6 \%$ of women), $41-60$ years $(12.2 \%$ men-12.5\% women), $61-80$ years $(8.4 \%$ men-9.8\% women). By comparing the sampled population to these total population figures, we deduce that male smokers represent a percentage of $47.8 \%$ of the total population, whereas ex-smokers represent $23.1 \%$. The percentage of female smolers is $21.6 \%$, whereas that of female ex-mokeis $2.4 \%$. In total, the percentily sf snckers is $34.4 \%$, whereas that oilex-smokers is $12.5 \%$.

Table 2 how:Comparatively the mean age of the participants from the population subgrcups, their mean smoking initiation age, the annual consumption of cigarettes (mean number of cigarettes smoked), smoking history in terms of pack-years, and the percentages of smokers and ex-smokers. Teachers are the group with the highest smoking prevalence (men $47.2 \%$, women $45.5 \%$ ), per capita consumption of tobacco, and the lowest rate of smoking cessation. Exercising persons have lower smoking prevalence rates (men $38.3 \%$, women $34.8 \%$ ), whereas medical doctors lie

Table 2 The mean age, the mean smoking initiation age, the annual consumption of cigarettes, the smoking history in terms of pack-years, and the percentages of smokers and non-smokers, in each special population sub-group

\begin{tabular}{|c|c|c|c|c|c|c|c|}
\hline & Number & Age & $\begin{array}{l}\text { Smoking } \\
\text { initiation } \\
\text { age }\end{array}$ & $\begin{array}{l}\text { Annual } \\
\text { consumption } \\
\text { (number of } \\
\text { cigarettes smoked) }\end{array}$ & $\begin{array}{l}\text { Smoking } \\
\text { history } \\
\text { (pack-years) }\end{array}$ & $\begin{array}{l}\text { Smokers } \\
\%\end{array}$ & $\begin{array}{l}\text { Ex-smokers } \\
\%\end{array}$ \\
\hline $\begin{array}{l}\text { High-school } \\
\text { students }\end{array}$ & 9,276 & $17.5 \pm 1.3$ & $14.4 \pm 1.8$ & 4,505 & $1.9 \pm 1.1$ & 29.6 & \\
\hline Students & 1,072 & $22.4 \pm 2.4$ & $17.8 \pm 2$ & 6,345 & $5.3 \pm 4.6$ & 40.7 & \\
\hline $\begin{array}{l}\text { Medical } \\
\text { Doctors }\end{array}$ & 597 & $36.9 \pm 8.2$ & $20.5 \pm 3.7$ & 6,113 & $22.7 \pm 21.6$ & 44.9 & 16.7 \\
\hline Teachers & 825 & $39.8 \pm 7.1$ & $19.8 \pm 4.1$ & 6,544 & $23.2 \pm 20.5$ & 46.4 & 14.2 \\
\hline $\begin{array}{c}\text { Exercising } \\
\text { persons }\end{array}$ & 624 & $29.2 \pm 9.6$ & $19 \pm 4$ & 5,579 & $9.5 \pm 7.9$ & 36.9 & 20.8 \\
\hline
\end{tabular}


Table 3 The percentage of positive answers to questions 6 to 9 of the ICRF smoking questionnaire (see Appendix A) for the general population and the special population sub-groups

\begin{tabular}{|c|c|c|c|c|}
\hline & $\begin{array}{l}\text { Question } 6 \text { - Tried to } \\
\text { give up smoking in } \\
\text { the last } 12 \text { months? }\end{array}$ & $\begin{array}{l}\text { Question } 7 \text { - Dr or nurse } \\
\text { advised you to give up } \\
\text { smoking in the last } 12 \\
\text { months? }\end{array}$ & $\begin{array}{l}\text { Question } 8 \text { - Is the } \\
\text { amount you smoke } \\
\text { harmful to your } \\
\text { health? }\end{array}$ & $\begin{array}{l}\text { Question } 9 \text { - Would } \\
\text { you like to give up } \\
\text { smoking? }\end{array}$ \\
\hline General population & 32.7 & 4 & 79.1 & 61.7 \\
\hline High-school students & & & 95.2 & \\
\hline Students & & & 96.6 & \\
\hline Medical Doctors & 29.3 & & 98.6 & 76.3 \\
\hline Teachers & 21.7 & 2.3 & 82.3 & 52.6 \\
\hline Exercising persons & 44.1 & 6.1 & 100 & 91.4 \\
\hline
\end{tabular}

in between the two groups (men $47.5 \%$, women $40.9 \%$ ). The prevalence of smoking is also high among university students (men $41.4 \%$, women $39.6 \%)$. It is remarkable that among high-school students both the prevalence of smoking $(32.6 \%$ in boys, $26.7 \%$ in girls, $29.6 \%$ in total) and the annual per capita consumption are high.

Table 3 shows the percentages of smokers in both the general population sample and in the population sub-groups who gave positive answers to questions 6 to 9 of the smoking questionnaire (see Appendix A). Answers to these questions demonstrate that awareness of the harmful impact of smoking is quite high $(79.1 \%)$, as is the intentim to stop smoking $(61.7 \%)$. A significant counter of smokers $(32.7 \%)$ had tried to st pp suckins over the previous tivelvemoliths puc only $4 \%$ had requested medical suppertio do so.

\section{Discussion}

The prevalence of smoking in the general population $(34.4 \%)$ was found to be comparable to the prevalence observed in other EU countries. According to WHO data the prevalence of smoking is $37 \%$ in Denmark, $36.5 \%$ in Spain, $36 \%$ in Norway, $34.5 \%$ in Austria, $33.5 \%$ in France, and $32 \%$ in Italy $[2,4]$. However, the differences between male and female smokers in Greece were more pronounced as compared to these aforementioned countries. The observed sex difference in smoking prevalence rates is in line with the reported prevalence in other South European countries (Spain - 48\% males and $25 \%$ females, France - $40 \%$ and $27 \%$, Italy $38 \%$ and $26 \%$ ) and different to those in the North European countries (Denmark - 37\% both for men and women, Norway - $36.4 \%$ and $35.5 \%$, Austria $42 \%$ and $27 \%$ ).

The smoking prevalence in women has increased dramatically over the last few years, as opposed to the decrease in men, due to the increased incidence of smoking in younger women - in line with our findings of a very high smoking prevalence rate in high-school girl students that exceeds the corresponding rate in the female general population. On the other hand, boys present a much lower percentage compared to the corresponding male general population. Similar percentages of smokers were also detected in a study of 2,032 high school students in 1989-90 conducted in the cities of Athens, Patras and Ioannina, i.e., 33.5\% in boys and $26 \%$ in girls [5]. According $-y$, it cap be assumed that the smoking habits of hig. sehool students in Greece hals hot changed since the last decade. ricularest, in 1995, 36\% of high school students were smokers, vine Cas in 1999 this figure was 46\% [6]. (II) Contrase, in the USA, where strict antismoking measures are in place, in 1998-99 12.8\% of high school students were smokers [7], showing that without any implementation of antismoking measures in schools, smoking prevalence cannot be expected to decline.

The medical students of the Aristotle University of Thessalonica present a high percentage of smokers. Compared to the younger age group (21-40) of the general population, male medical students have a much lower smoking rate compared to men generally, whereas female medical students have the same smoking rates as women in the general population. This implies that female medical students do not show the high degree of awareness of the dangers of smoking as might be expected. In 1989, in 14 European countries, the percentage of medical students who were smokers was $21 \%$ [8]. For the medical students in this study, the per capita consumption rate of cigarettes was particularly high at 6,345 . In comparison, the corresponding consumption in medical students in Pakistan was just 3,103 cigarettes [9].

The medical doctors of the National Health System have a smoking prevalence of $44.9 \%$. Again, male doctors have lower smoking prevalence rates than the general population of the corresponding 
age, unlike women. According to European Union data from 1992-93, the percentage of smokers amongst medical doctors was $37 \%$, with Spanish doctors showing the highest prevalence rates at $44 \%$, followed by Italy with $41 \%$, and Greece with $39 \%$, whereas the UK ranked last with a percentage of $12 \%[10,11]$. More recent data from Italy show that in a hospital staff sample of 959 subjects aged $31 \pm 9$ years, the prevalence of smoking was $44 \%$, and in medical doctors, with a mean age of 40 years old, it was 39\% [12].

Forty-six percent of the Greek teachers in this study are smokers. This percentage is very high, particularly in women. According to the 1992-93 European Union data, $26 \%$ of teachers in the European Union were smokers. Italy was ranked first with a percentage of $37 \%$, Spain second with a percentage of $35 \%$, Denmark third with a percentage of $34 \%$ and the UK last with a percentage of $13 \%$. Greece, with a percentage of $30 \%$, was ranked fourth $[10,11]$. According to recent data from India, $51 \%$ (73.9\% of men and $13.9 \%$ of women) of Indian teachers are smokers [13].

Exercising persons present a percentage of $36.9 \%$ smokers, considerably lower in both men and women compared to the general population. Exercise might be expected to affect a person's attitude positively against smoking, within che concept of a healthier lifestyle. Thio ittitude is also detected in a studu tof 1.02 students from Italy, whers the correl ation between exficis rand smoking showed that wher eas sniching, incidence increases according to age, exercising persons present an opposite trend [14]. Also, the frequency of physical exercise is inversely associated with smoking [15]. Participating in exercise and avoiding smoking are linked. The annual per capita consumption of tobacco is almost the same among students, medical doctors and teachers, whereas it is lower in exercising persons, meaning that people who exercise not only have a lower smoking prevalence, but they also smoke less cigarettes. Moreover, participating in exercise seems to contribute to quitting smoking, since among exercising people there is the highest percentage of ex-smokers - although they were younger compared to the other groups.

Comparison between the adult sub-groups studied shows that teachers present the highest rates of smoking prevalence and per capita consumption of tobacco, and the lowest rates of smoking cessation. Medical doctors are next, and then exercising persons, who are living a healthier way of life. It would seem that the role of theoretical knowledge and experiences (medical doctors, teachers) about the harmful impact of tobacco smoking is not as important as the adoption of a healthy lifestyle (as shown by exercising persons) in lowering smoking prevalence rates.

The majority of smokers are aware of the harmful impact of smoking (79.1\%), but this knowledge could be further disseminated. In comparison, in Saudi Arabia among 819 interviewed high-school students over 15 years old, 95\% were aware of the effects of tobacco [16], and in Pakistan $98 \%$ of first-year medical students were aware that passive smoking is harmful [9].

A significant percentage of smokers in this study intended to quit smoking (61.7\%) and a large number - $32.7 \%$ - had tried to stop but had been unsuccessful. This may be due to the lack of medical assistance, which was requested by only $4 \%$. According to international data, the success figures for smoking cessation are more than doubled with the help of special medication administered under medical guidance [17]. This treatment would be more effective within the scope of a co-ordinated antismoking campaign, as recently started in Greece with the launch of the Greek Ministry of Health and Welfare initiative and the foundation of special smofing cessation consulting centers in 15 main nospitals throughout the count : [18]. In the USA, their antismoking Cirnpaisn has achieved excellent results: in 1965, $52 \%$ of men in th GSA were smokers, in 1998 the figurle $\mathrm{Na} 24 \%$, and the aim is to reduce this to $12 \%$ by 2010 [19]. We believe that the recent initiatives undertaken by the Greek Ministry of Health and Welfare will have the same effect in Greece.

\section{Conclusion}

The prevalence of smoking in Northern Greece is high. High school and university students present with high smoking rates, whereas medical doctors and teachers have similar smoking rates to the general population. A decreasing prevalence in men and an increasing prevalence in women characterizes the diachronic development of smoking habits in Greece. An intensification of preventive antismoking measures is required, particularly aimed at the youth population and women.

\section{Potential conflict of interest}

There are no conflicts of interest to declare.

\section{Acknowledgements}

The Governmental Department, the Region of Western Macedonia, Greece, financially supported this study. 


\section{Appendix A. ICRF Study Group Smoking questionnaire}

\begin{tabular}{|c|c|}
\hline \multirow{2}{*}{ 1. Are you or have you ever been a smoker? } & Yes \\
\hline & No \\
\hline \multicolumn{2}{|l|}{ 2. At what age did you first smoke regularly (at least once a day)? } \\
\hline \multicolumn{2}{|l|}{ 3. For how many years altogether have you smoked/did you smoke regularly? } \\
\hline \multirow{2}{*}{ 4. Do you CURRENTLY smoke at least once a day? } & Yes \\
\hline & No \\
\hline 5. On average, how many cigarettes do you smoke a day? & $\square$ cigarettes per day \\
\hline \multirow[t]{2}{*}{ 6. In the last 12 months have you SERIOUSLY tried to give up smoking? } & Yes \\
\hline & No \\
\hline \multirow[t]{2}{*}{ 7. In the last 12 months has a doctor or nurse advised you to give up smoking? } & Yes \\
\hline & No \\
\hline \multirow{3}{*}{ 8. Do you think the amount you smoke is harmful to YOUR health? } & Yes \\
\hline & No \\
\hline & Don't know \\
\hline \multirow{3}{*}{ 9. Would you like to give up smoking? } & Yes \\
\hline & No \\
\hline & Don't need to \\
\hline 10. Sex & $\square$ male \\
\hline
\end{tabular}

\section{References}

[1] International Agency for Research on Cancer. Cancer in the European Union in 1990. EUCAN 90 Version 1.1, Cop vriş ht IARC 1996. International Agency far Resear in in eancer, Lyon 1997.

[2] World Health prgaliktip?. Tobacco or Health Firs

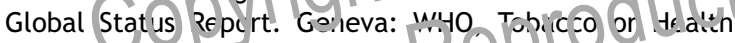
Programme; 1997.

[3] Fowler G. Smoking Cessation. The role of general practitioners, nurses and pharmacists. In: Bolliger CT, Fargerström KO, editors. The tobacco epidemic. Progress in Respiratory Research 1997; 28: 165-77.

[4] World Health Organization. Tobacco or Health: A Global Status Report. Geneva: WHO; 1998.

[5] Marselos M, Fragidis H, Michalopoulos V. Diachronic study on smoking. Iatriki 1993;63:140-6.

[6] Prevalence of cigarette smoking among secondary school students- Budapest, Hungary, 1995 and 1999. MMWR Morb Mortal Wkly Rep 2000;49:438-41.

[7] Youth tobacco surveillance - United States, 1998-1999. MMWR CDC Surveill Summ 2000;49:1-94.

[8] Tessier JF, Freour P, Crofton J, Kombou L. Habit of smoking and attitudes of medical students towards smoking and anti/smoking campaigns in fourteen European countries. Eur J Epidemiol 1989;5:311-21.

[9] Hussain SF, Moid I, Khan JA. Attitudes of Asian medical students towards smoking. Thorax 1995;50:996-7.
[10] Bosanquet N. Europe and Tohacc $0.9,1,1727$; : 4:370-2.

[11] Piha T, Beselink E Lore? AD To'vacco and health. World Hiealth'sta $199 ; ; 6.188-94$.

12] Vadii.S, Bertoletti R. Rastelli V, Ravelli L, Donner CF. Personal smoling 2abit and attitude towards smoking amcin the hellth starf of a general hospital. Monaldi Arch (hest Dis 1998;53:74-8.

[13] Pandey GK, Raut DK, Hazra S, Vajpayee A, Pandey A, Chatterjee P. Patterns of tobacco use amongst schoolteachers. Indian J Public Health 2001;45:82-7.

[14] Donato F, Assanelli D, Chiesa R, Poeta ML, Tomasoni V, Turla C. Cigarette smoking and sports participation in adolescents: a cross-sectional survey among high school students in Italy. Subst Use Misuse 1997;32:1555-72.

[15] Holmen TL, Barrett-Connor E, Clausen J, Holmen J, Bjermer L. Physical exercise, sports, and lung function in smoking versus nonsmoking adolescents. Eur Respir J 2002;19:8-15.

[16] Al-Yousaf MA, Karim A. Prevalence of smoking among high school students. Saudi Med J 2001;22:872-4.

[17] Hurt RD, Sachs DP, Glover ED, Offord KP, Johnston JA, Dale LC, et al. A comparison of sustained-release bupropion and placebo for smoking cessation. N Engl J Med 1997;227:1195-202.

[18] Ministry of Health and Welfare of Greece. World No-smoking Day, May 31 2002. Available from: URL: http://www.ypyp.gr/.

[19] Cigarette smoking among adults - United States, 1999. MMWR Morb Mortal Wkly Rep 2001;50:869-73.

Available online at www.sciencedirect.com

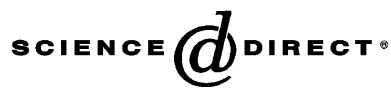

